\title{
Does hearing the patient perspective improve consultation skills? An exploratory randomised controlled trial in medical undergraduate education
}

\author{
Rosamund Snow ${ }^{1 *}$, Joanna Crocker $^{12}$, Katherine Talbot ${ }^{3}$, Jane Moore ${ }^{3}$, Helen Salisbury ${ }^{1}$ \\ Author information: \\ ${ }^{1}$ Health Experiences Institute, Nuffield Department of Primary Care Health Sciences, \\ University of Oxford \\ ${ }^{2}$ NIHR Oxford Biomedical Research Centre, Oxford \\ ${ }^{3}$ Nuffield Department of Obstetrics \& Gynaecology, University of Oxford \\ *Correspondence: Rosamund Snow, Nuffield Department of Primary Care Health Sciences, \\ University of Oxford, Woodstock Road, Oxford OX2 6GG. Tel: +44 1865 617767; E-mail: \\ Rosamund.snow@phc.ox.ac.uk
}

\begin{abstract}
Context

Medical students may benefit from hearing patients' experiences, but it is not clear whether offering patients' viewpoints on medical procedures has any measurable effect on students' skills or abilities. There are also ethical and practical issues in inviting lay people to repeatedly relive their experiences for students' benefit. This study explored the effect on students' exam performance of watching video clips of women describing their experiences of colposcopy. We explored whether students who had viewed such videos performed differently from those who had not heard the patient perspective.
\end{abstract}

\section{Methods}

Medical students in their penultimate year were randomised to receive one of two online learning modules. The experimental group saw a video of patients describing their experiences of colposcopy, while the control group viewed a clinician describing the procedure. All other elements of the module were the same. Students then completed a multiple choice questionnaire (MCQ) and were assessed by a blinded clinical examiner in an Objective Structured Clinical Examination (OSCE) with a simulated patient (SP). The SP, also blinded, scored students using the Doctors' Interpersonal Skills Questionnaire (DISQ). Students then rated the module's effect on their skills and confidence. Regression analyses were used to compare the effect of the two modules on these outcomes, adjusting for gender and graduate entry.

\section{Results}

88 students were randomised. The experimental group performed better in the OSCE than the control group (odds ratio 2.7 [95\% C.I. 1.2 to 6.1]; $p=0.016$ ). They also reported 
significantly more confidence in several key areas, including comfort with patients' emotional reactions (odds ratio 6.4 [95\% C.I. 2.7 to 14.9]; $p<0.0005$ ). There was no significant difference in DISQ or MCQ score between the two groups.

\section{Conclusions}

Teaching that includes recorded elements of real patient experience can significantly improve students' examination performance and confidence.

\section{Introduction}

Including the patient or carer voice in the education of healthcare professionals is increasingly considered to be important. In recent years it has been specifically recommended by the UK bodies that govern education in this field(1-4). Often, this is done by patients coming, in person, to describe their experience or illness story for students as part of an existing clinical course $(5,6)$. Research has repeatedly shown that interacting with patients and carers, and hearing their stories, can improve students' knowledge, attitudes and confidence(7-10).There is also evidence that involving real patients may be better for teaching communication than involving simulated patients (11). However, it is not always feasible or ethical to ask patients to return again and again to describe what may be unpleasant or upsetting experiences to successive cohorts of clinicians in training $(12,13)$. In addition, much of the research done to date involves relatively complex interventions, for example where patients and carers may discuss their story with students in groups or over time, and/or offer active feedback on communication skills (14). It is not always clear, therefore, which elements of a patient/carer educational intervention affect student outcomes.

Our study explored the effect on student performance and confidence of viewing a video of women describing their experiences of investigations for cervical abnormalities.

\section{Methods}

\section{Recruitment and randomisation of participants}

University of Oxford medical students in their fifth (penultimate) year during 2014-2015 were offered the opportunity to participate in this study. There were no exclusion criteria. Five cohorts of students were recruited during the year. The study took place in the introductory two week lecture session at the start of their obstetrics and gynaecology course, before they had gained any clinical experience. Most of those who did not take part were unable to do so because they had chosen to take up short-term clinical training opportunities overseas ('electives'). Within each cohort, as participants arrived to take part, they were randomised by a researcher (RS) consecutively assigning them to one of two educational modules. Students knew that they had been randomised to module ' $A$ ' or ' $B$ ', but were not told how these modules differed. 


\section{Module content}

The modules were both online interactive programmes following two patients through the diagnosis and management of pre-cancerous changes in the cervix. Both modules covered the NHS cervical screening call and re-call programme, the natural history of cervical cancer and the diagnosis and management of pre-cancerous changes. Information was conveyed through video clips, images and text. The modules were expected to take 20 minutes to complete but no time limit was imposed.

As part of the module, the control group of students took an interactive online lesson about cervical screening and the clinical management of cervical abnormalities, which included a series of video clips in which a female doctor described the case histories of two patients ('doctor module'). The experimental group of students took an online lesson identical in every respect, except that instead of featuring the doctor, the clips were of the two patients themselves describing their personal experience of the relevant procedures, taken from the Health Experiences Research Group archive ('patient module'). Both modules offered the same clinical information, ensuring that students would be given all the facts they would later be tested on. However, in the patient interviews, women who had experienced colposcopy spoke about their initial fears and concerns, described personal pain responses and what that meant for their daily life and ability to work, and talked about postprocedural issues such as the emotional strain of waiting for results. By contrast, the 'doctor module' offered textbook information about common complications such as pain "of varying severity", and provided general recommendations for returning to work and resumption of sexual activity. Both modules included information on the time it took to process and deliver results. The modules were developed following a pilot of the experimental version with an earlier cohort of students to ensure ease of use and educational value. The full modules are available on request from the authors.

\section{Data collection}

Immediately after taking the module, both groups were given a 20 -item untimed Multiple Choice Questionnaire (MCQ) testing their knowledge of the module content. They then took an Objective Structured Clinical Examination (OSCE), written by a gynaecologist with six years of exam-setting experience, in which they were asked to engage in a consultation with a simulated patient, answering the patient's questions about colposcopy (see Fig. 1). The simulated patient (SP) was played by professional actors with experience in medical role play. Assessments were done in the rooms where students would normally take their endof-rotation examinations. Each OSCE was marked on a standard four-point scale (Fail/Borderline Fail/Clear Pass/High Pass) by a clinical examiner. Scores were based on the students' ability to explore the patient's concerns, explain accurately what a colposcopy is and how it is performed, and answer the patient's questions about timescales for receiving results. The SP scored students on a five-point scale (Poor/Fair/Good/Very Good/Excellent) using the Doctors' Interpersonal Skills Questionnaire (DISQ), adapted to reference 'students' rather than 'doctors'. The DISQ is a reliable and valid tool for assessing communications 
competence in clinical consultations, which has been tested with real-life patients (15).

Examiners and SPs were all blinded to which module students had been assigned to. Due to practical considerations, it was not always possible to have the same clinical examiners and SPs examining each cohort. Each time a cohort took part, three identical OSCE stations were provided at the same time to ensure speedy throughput of students. Over the five sessions, six examiners and six SPs took part.

After completing the module and assessments, students were asked to complete a questionnaire about their experience of taking the module. This used a 5 point scale (not at all/a little/somewhat/quite a bit/a lot) to score whether the module increased their knowledge of the topic, improved their ability to discuss cervical screening, improved their understanding of how to communicate with patients, increased their comfort level in discussing the topic with patients, increased their ability to respond to patients' emotions, or would affect their future practice (see Fig 3.)

Data on the participants' gender and cohort were recorded, alongside their overall OSCE scores, DISQ scores, and their self evaluations. Some students were "graduate entry", meaning that they had entered medical school having taken a first degree in a different discipline, and this was also recorded.

Since this was an exploratory study, we looked at a range of outcomes, specifically differences between the groups on their DISQ, MCQ and OSCE scores, and students' selfevaluation.

\section{Data analysis}

Consistent with work done by Greco et al, the twelve DISQ scores were averaged to calculate an overall "Interpersonal Skills Index" (ISI), expressed as a percentage(16). The ISI and students' MCQ scores were normally distributed. OSCE scores and students' evaluation scores were treated as ordinal variables.

Within the literature on patient-clinician interaction, there is evidence that male and female healthcare professionals interact with patients in slightly different ways, with women sometimes scoring more highly on empathy, patient-centredness and communication (1719). In addition, although the students in our study were very close in age, a minority had come to medical school having completed a first degree in a different subject. Anecdotal evidence suggests that these "graduate entry" students may have a more mature communication style. We therefore decided to adjust for gender and graduate entry in our analyses of outcome measures related to students' performance (that is, ISI and OSCE scores).

We explored associations between group (experimental vs. control) and MCQ and ISI scores using linear regression. For the OSCE and evaluation scores we performed proportional odds ordinal regression analyses to obtain the odds ratio for a one point improvement in score associated with the experimental group compared to the control group. We used IBM SPSS Statistics 22 and Microsoft Excel 2010 to carry out the analyses. 


\section{Results}

Figure 3 shows the flow of participants from eligibility assessment to analysis. From the 135 students in five cohorts who were asked to participate, $88(65 \%)$ individual students agreed to take part. All participants completed their allocated learning module and multiple choice questionnaire, but one withdrew before taking part in the OSCE and self-evaluation. Students from the control and experimental groups were evenly distributed across examiners ( $p=0.92)$ and SPs $(p=0.24)$.

Significant differences were found between the two groups' OSCE scores (see Table 1).

Being in the experimental ('patient module') group meant that a student was 2.8 times more likely to score an extra point in their clinical exam than if they had been in the control ('doctor module') group.

The experimental group also assessed themselves as significantly more confident in their understanding of how to communicate with patients about cervical screening, their own comfort in discussing screening, and their comfort in responding to patients' emotional reactions. They also reported significantly more willingness than the control group to change their future practice (see Table 2).

There were no significant differences between the experimental and control group on any other outcome measures.

Full results are shown in Tables 1 and 2 .

Table 1-Examiner-reported outcomes

Table 2-Student-reported outcomes

\section{Discussion}

The module that included patient experience appeared to have a significant impact on students' clinical exam performance and their self-reported comfort and confidence in their communication skills. It did not make any difference to their performance in the written test or their general interpersonal skills in a role play situation.

It is not a surprise that students' written test results did not show differences between the two groups. The written test dealt with procedures and diagnoses rather than communications about, or emotional responses to, those procedures. It is worth noting that the 'patient module' apparently did not distract students from learning these clinical facts. It is more surprising that there were no significant differences between the two groups' scores on the DISQ Interpersonal Skills Index. However, this could be a result of consistent communications teaching on other parts of the overall course. All students entering the study had already experienced a series of eight experiential clinical communication workshops in the previous year of the medical course. In this context, it is perhaps understandable that the non-specific interpersonal skills tested in DISQ remained similar no matter which module the students took.

There may be a number of explanations for the experimental group's improved OSCE performance. Firstly, they may simply have entered the exam feeling more emotionally prepared than their peers. These students reported significantly higher levels of comfort with emotions following the 'patient module', probably as a result of having had the chance 
to hear and reflect on real patients' concerns. This opportunity is perhaps especially valuable for interactions around colposcopy, which students may find difficult because of the sensitivity of the topic and potential for embarrassment. This emotional mindset, while it made no difference to students' written exam results, may have allowed the experimental group to perform at a higher level in their OSCE clinical assessment.

Secondly, they may have felt more able to communicate information about colposcopy because of their exposure to patients' priorities around this specific procedure. As the similarity in scores for Interpersonal Skills demonstrates, exposure to patient experience does not appear to improve communication in a general way; rather it teaches students important context for the clinical material. In this instance, these included practical issues arising from post-procedural pain and bleeding, and the impact of waiting for results. Familiarity with these facts may explain the experimental group's significantly higher level of self-assessed "ability to communicate" with patients, and their comfort discussing the issues around colposcopy. Again, this may have added to the experimental group's readiness for the simulated consultation.

A third factor could be that having information presented by a real patient in lay language allowed the experimental group to access that information more easily during the consultation scenario.

In summary, hearing real patients describing what mattered to them before, during, and after a medical procedure seems to have prepared students more adequately for a face-toface encounter than simply absorbing medically prioritised, clinically relevant facts.

\section{Limitations}

There are several limitations in the design of this exploratory trial. In particular, Oxford has a traditional six-year course in which students have regular patient contact only in the final three years of clinical teaching. This differs from many other medical schools, which, by following a more integrated approach, have more patient contact throughout the course. Therefore, the effect of hearing real patient stories may have a greater impact for Oxford students, who in year five would have had only 12 to 18 months' contact with patients. Students at schools with more developed patient tutor programmes might also respond in a different way. The topic, an intimate procedure for further investigation for cancer, is a sensitive one; less emotive patient accounts might have had less impact on the students. Students were also examined immediately after being exposed to the online modules; we therefore cannot say whether the results we found would hold true over a longer period between learning and testing. In addition, for this exploratory trial, numbers of participants were relatively low; a larger sample might be needed to detect possible differences in the Interpersonal Skills Index.

Participation was voluntary and it is possible that the absent students might have responded differently to the modules than their peers. It is also possible that during the course of the year, students in earlier cohorts discussed the study with their peers in later cohorts, although they were asked not to do so. 
Finally, actors who simulate a patient scenario again and again may not respond to the students' interpersonal skills in the same way as women facing a real-life one-off consultation about an unfamiliar procedure. The DISQ questionnaire has been validated with real patients, but not specifically with patients facing investigation for possible cancer. It is therefore possible that in a real world scenario, patients might rate students differently.

\section{Conclusions}

Use of pre-recorded patient experience alongside more traditional teaching materials may improve students' confidence and performance in examined clinical consultations. Since there are ethical and resource considerations involved in asking real patients to repeatedly recount personal experiences as part of medical education, recorded patient interviews which are proven to benefit students' performance may provide a more acceptable alternative. Future work is required to explore whether our results can be replicated in different topic areas, over longer periods of time, with larger groups of students, and with students who have had different styles of general teaching.

\section{Contributors}

$\mathrm{KT}$, JM and HS made substantial contributions to the study conception and design. RS collected and analysed all data, and wrote the first draft of the manuscript. JC made substantial contributions to data analysis and interpretation, and revised multiple drafts. HS, JC, JM and KT revised the final drafts. All authors approved the final manuscript for submission. All authors agreed to be accountable for all aspects of the work.

\section{Acknowledgements}

The authors wish to thank the medical students who participated in this study, Katy Vincent and Alecia Nickless for their advice on statistics, the SPs and clinical examiners who conducted the OSCE exams, and Natalie Colborne, James Matejtschuk and Damion Young for help and support with the creation and management of the teaching videos.

\section{Funding}

This project was funded by the Nuffield Oxford Hospital Trust.

\section{Conflicts of interest}

None.

\section{Ethical approval}

This study was reviewed and approved by the University of Oxford's Central University Research Ethics Committee. 
Figures/tables

Fig 1. Objective Structured Clinical Examination (OSCE)

Information offered to student: You are an F2 in general practice. Mrs Gina Evans is a 45 year old patient who has just had an abnormal smear-moderate dyskariosis and so has been invited for colposcopy. She has come to see you to discuss this.

Assessment criteria used by assessor:

Exploring the patient's concerns

Asks patient what she wants from consultation

Active listening

Invites patient to ask questions

Explaining what a colposcopy is

Establishes patient's prior knowledge

Uses appropriate (non jargon) language

Checks understanding

Explains that it investigates abnormal cells found on smear

Plan or do further treatment to correct abnormalities

Explaining what a colposcopy is like

How patient will be lying

What procedures will take place (stains, LLETZ, biopsy)

Pain, need for anaesthetic

Complications

Appropriate answers to specific questions (all SPs to ask these):

Return to work day

Rough time before patient can expect results (given in module as 1-2 weeks)

Global Score: 1 = Fail; 2 = Borderline Fail; 3 = Clear Pass; 4 = High Pass.

Fig 2. Student assessment of learning

\begin{tabular}{|c|c|c|c|c|c|}
\hline \multicolumn{2}{|c|}{ Not at all } & \multicolumn{2}{|c|}{$\rightarrow$} & \multicolumn{2}{|c|}{ A lot } \\
\hline $\begin{array}{l}\text { How much did this module } \\
\text { increase your knowledge of } \\
\text { cervical screening? }\end{array}$ & 1 & 2 & 3 & 4 & 5 \\
\hline $\begin{array}{l}\text { How much do you think this } \\
\text { module will increase your ability } \\
\text { to discuss cervical screening with } \\
\text { patients? }\end{array}$ & 1 & 2 & 3 & 4 & 5 \\
\hline $\begin{array}{l}\text { How much did this module } \\
\text { increase your understanding of } \\
\text { how to communicate with } \\
\text { patients with respect to cervical } \\
\text { screening? }\end{array}$ & 1 & 2 & 3 & 4 & 5 \\
\hline
\end{tabular}




\begin{tabular}{|c|c|c|c|c|c|}
\hline $\begin{array}{l}\text { How much do you think this } \\
\text { module will increase your comfort } \\
\text { when discussing cervical } \\
\text { screening? }\end{array}$ & 1 & 2 & 3 & 4 & 5 \\
\hline $\begin{array}{l}\text { How much do you think this } \\
\text { module will increase your comfort } \\
\text { in responding to a patient's } \\
\text { emotional reaction to cervical } \\
\text { screening? }\end{array}$ & 1 & 2 & 3 & 4 & 5 \\
\hline $\begin{array}{l}\text { Will this module change your } \\
\text { future practices? }\end{array}$ & 1 & 2 & 3 & 4 & 5 \\
\hline
\end{tabular}

Figure 3. Flow of participants from eligibility assessment to analysis.

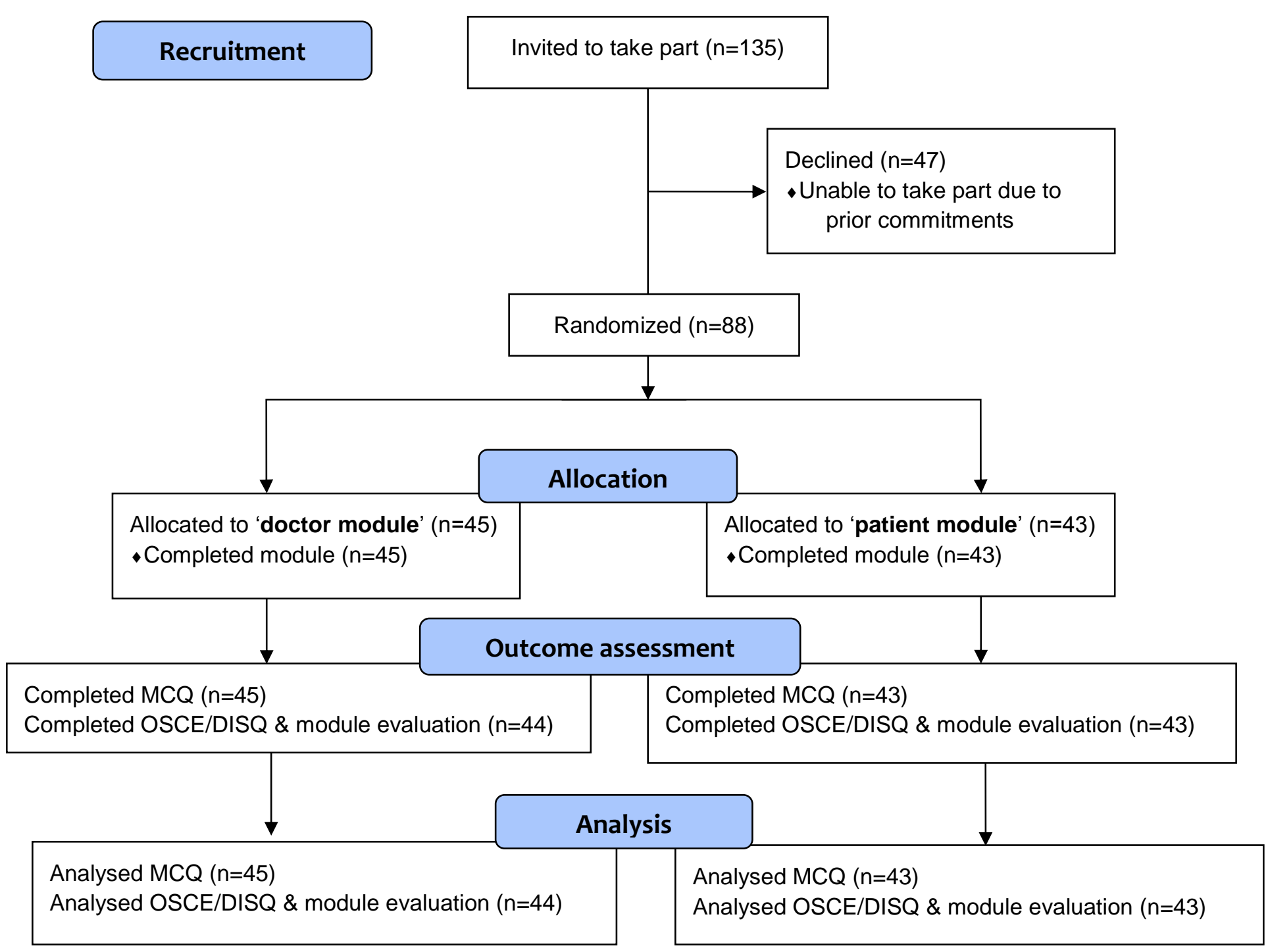


Table 1. Examiner-reported outcomes

\begin{tabular}{|c|c|c|c|c|c|c|}
\hline \multicolumn{2}{|l|}{ Outcome } & $\begin{array}{l}\text { Control } \\
\text { group }\end{array}$ & $\begin{array}{l}\text { Experimental } \\
\text { group }\end{array}$ & $\begin{array}{l}\text { Crude } \\
\text { estimate } \\
\text { (95\% } \\
\text { C.I.) }\end{array}$ & $\begin{array}{l}\text { Adjusted } \\
\text { estimate** } \\
(95 \% \text { C.I.) }\end{array}$ & $p$-value \\
\hline \multicolumn{2}{|c|}{$\begin{array}{l}\text { ISI (average of all DISQ) } \\
\text { as a percentage }\end{array}$} & $\begin{array}{l}\text { Mean } \\
68.9 \% \\
\text { (s.d. } \\
\text { 18.6\%) }\end{array}$ & $\begin{array}{l}\text { Mean } 75.1 \% \\
\text { s.d. }(17.35 \%)\end{array}$ & $\begin{array}{l}\text { Beta co- } \\
\text { efficient: } \\
6.27 \text { (- } \\
1.49 \text { to } \\
14.03 \text { ) }\end{array}$ & $\begin{array}{l}\text { Beta co- } \\
\text { efficient: } \\
5.72(-2.13 \\
\text { to } 13.57)\end{array}$ & 0.15 \\
\hline \multirow[t]{4}{*}{ OSCE score } & Fail & $3(6.8 \%)$ & $0(0.0 \%)$ & \multirow{4}{*}{$\begin{array}{l}\text { Odds } \\
\text { ratio } 2.7 \\
(1.2 \text { to } \\
6.1)\end{array}$} & \multirow{4}{*}{$\begin{array}{l}\text { Odds ratio } \\
2.8(1.2 \text { to } \\
6.4)\end{array}$} & \multirow[t]{4}{*}{$0.013^{*}$} \\
\hline & $\begin{array}{l}\text { Borderline } \\
\text { fail }\end{array}$ & $11(25.0 \%)$ & $8(18.6 \%)$ & & & \\
\hline & Pass & 22 (50.0\%) & $17(39.5 \%)$ & & & \\
\hline & High pass & $8(18.2 \%)$ & 18 (41.9\%) & & & \\
\hline \multicolumn{2}{|l|}{$\begin{array}{l}\text { MCQ score } \\
\text { out of } 20\end{array}$} & $\begin{array}{l}\text { Mean } 18.2 \\
\text { (s.d. 1.4) }\end{array}$ & $\begin{array}{l}\text { Mean } 17.9 \text { (s.d. } \\
1.4 \text { ) }\end{array}$ & $\begin{array}{l}\text { Beta co- } \\
\text { efficient: } \\
-0.27 \text { (- } \\
0.87 \text { to } \\
0.33 \text { ) }\end{array}$ & N/A & 0.37 \\
\hline
\end{tabular}

$* \mathrm{p}<0.05$

** ISI and OSCE score adjusted for gender and graduate entry

Table 2. Student-reported outcomes

\begin{tabular}{|c|c|c|c|c|c|}
\hline \multicolumn{2}{|c|}{$\begin{array}{l}\text { Outcome: } \\
\text { How much did this module... }\end{array}$} & $\begin{array}{l}\text { Control } \\
\text { group }\end{array}$ & $\begin{array}{l}\text { Experimental } \\
\text { group }\end{array}$ & $\begin{array}{l}\text { Odds ratio } \\
\text { (95\% C.I.) }\end{array}$ & $p$-value \\
\hline \multirow{5}{*}{$\begin{array}{l}\text {... increase your } \\
\text { knowledge of } \\
\text { cervical } \\
\text { screening? }\end{array}$} & Not at all & $0(0.0 \%)$ & $0(0.0 \%)$ & \multirow{5}{*}{$\begin{array}{l}1.0(0.5 \text { to } \\
2.2)\end{array}$} & \multirow[t]{5}{*}{0.97} \\
\hline & A little & 0 (0.0\%) & $0(0.0 \%)$ & & \\
\hline & Somewhat & 8 (18.2\%) & $4(9.3 \%)$ & & \\
\hline & Quite a bit & 19 (43.2\%) & 25 (58.1\%) & & \\
\hline & A lot & 17 (38.6\%) & $14(32.6 \%)$ & & \\
\hline \multirow{2}{*}{$\begin{array}{l}\text {...increase your } \\
\text { ability to }\end{array}$} & Not at all & $0(0.0 \%)$ & $0(0.0 \%)$ & \multirow{2}{*}{$\begin{array}{l}1.5(0.7 \text { to } \\
3.3)\end{array}$} & \multirow[t]{2}{*}{0.35} \\
\hline & A little & $2(4 / 5 \%)$ & $0(0.0 \%)$ & & \\
\hline
\end{tabular}




\begin{tabular}{|c|c|c|c|c|c|}
\hline \multirow{3}{*}{$\begin{array}{l}\text { discuss cervical } \\
\text { screening with } \\
\text { patients? }\end{array}$} & Somewhat & 9 (20.5\%) & 5 (11.6\%) & & \\
\hline & Quite a bit & $20(45.5 \%)$ & 25 (58.1\%) & & \\
\hline & A lot & $13(29.5 \%)$ & $13(30.2 \%)$ & & \\
\hline \multirow{5}{*}{$\begin{array}{l}\text {...increase your } \\
\text { understanding } \\
\text { of how to } \\
\text { communicate } \\
\text { with patients } \\
\text { with respect to } \\
\text { cervical } \\
\text { screening? }\end{array}$} & Not at all & 2 (4.5\%) & $0(0.0 \%)$ & \multirow{5}{*}{$\begin{array}{l}4.3 \text { (1.0 to } \\
5.0)\end{array}$} & \multirow[t]{5}{*}{$0.001 *$} \\
\hline & A little & $11(25.0 \%)$ & $3(7.0 \%)$ & & \\
\hline & Somewhat & $16(36.4 \%)$ & $8(18.6 \%)$ & & \\
\hline & Quite a bit & $10(22.7 \%)$ & 25 (58.1\%) & & \\
\hline & A lot & 5 (11.4\%) & 7 (16.3\%) & & \\
\hline \multirow{5}{*}{$\begin{array}{l}\text {...increase your } \\
\text { comfort when } \\
\text { discussing } \\
\text { cervical } \\
\text { screening? }\end{array}$} & Not at all & $1(2.3 \%)$ & $0(0.0 \%)$ & \multirow{5}{*}{$\begin{array}{l}2.3 \\
(1.0 \text { to } \\
5.0)\end{array}$} & \multirow[t]{5}{*}{$0.042 *$} \\
\hline & A little & 4 (9.1\%) & $2(4.7 \%)$ & & \\
\hline & Somewhat & $14(31.8 \%)$ & 10 (23.3\%) & & \\
\hline & Quite a bit & $19(43.2 \%)$ & $18(41.9 \%)$ & & \\
\hline & A lot & $6(13.6 \%)$ & $13(30.2 \%)$ & & \\
\hline \multirow{5}{*}{$\begin{array}{l}\text {...increase your } \\
\text { comfort in } \\
\text { responding to a } \\
\text { patient's } \\
\text { emotional } \\
\text { reaction to } \\
\text { cervical } \\
\text { screening? }\end{array}$} & Not at all & $1(2.3 \%)$ & $0(0.0 \%)$ & \multirow{5}{*}{$\begin{array}{l}6.4 \\
(2.7 \text { to } \\
14.9)\end{array}$} & \multirow[t]{5}{*}{$<0.0005^{*}$} \\
\hline & A little & $4(91 \%)$ & $2(4.6 \%)$ & & \\
\hline & Somewhat & $14(31.8 \%)$ & $10(23.3 \%)$ & & \\
\hline & Quite a bit & $19(43.2 \%)$ & 18 (41.9\%) & & \\
\hline & A lot & 6 (13.6\%) & $13(30.2 \%)$ & & \\
\hline \multirow{5}{*}{$\begin{array}{l}\text {...change your } \\
\text { future } \\
\text { practices? }\end{array}$} & Not at all & 0 (0.0\%) & $0(0.0 \%)$ & \multirow{5}{*}{$\begin{array}{l}2.9 \\
(1.3 \text { to } \\
6.5)\end{array}$} & \multirow[t]{5}{*}{$0.009 *$} \\
\hline & A little & 9 (20.5\%) & $4(9.3 \%)$ & & \\
\hline & Somewhat & $19(43.2 \%)$ & $11(25.6 \%)$ & & \\
\hline & Quite a bit & $12(27.3 \%)$ & $20(46.5 \%)$ & & \\
\hline & A lot & 4 (9.1\%) & 8 (18.6\%) & & \\
\hline
\end{tabular}

$* p<0.05$

\section{References}

1. GMC. Tomorrow's Doctors. London: General Medical Council; 2009. 
2. GMC. Patient and public involvement in undergraduate medical education. London: General Medical Council; 2009.

3. NMC. Standards for Pre-Registration Nursing Education. London: Nursing and Midwifery Council, 2010.

4. HCPC. Role brief and requirements for lay visitors. London: Health and Care Professions Council, 2014.

5. Braeckman L, 't Kint L, Bekaert M, Cobbaut L, Janssens H. Comparison of two casebased learning conditions with real patients in teaching occupational medicine. Medical Teacher. 2014;36(4):340-6.

6. Jain S, Foster E, Biery N, Boyle V. Patients with disabilities as teachers. Family medicine. 2013;45(1):37-9.

7. Jha V, Setna Z, Al-Hity A, Quinton ND, Roberts TE. Patient involvement in teaching and assessing intimate examination skills: a systematic review. Medical Education. 2010;44(4):347-57.

8. Morgan A, Jones D. Perceptions of service user and carer involvement in healthcare education and impact on students' knowledge and practice: a literature review. Medical Teacher. 2009;31(2):82-95.

9. Spencer J, Godolphin W, Karpenko N, Towle A. Report: Can patients be teachers? Involving patients and service users in healthcare professionals' education. London: The Health Foundation; 2011.

10. Towle A, Bainbridge L, Godolphin W, Katz A, Kline C, Lown B, et al. Active patient involvement in the education of health professionals. Medical Education. 2010;44(1):64-74.

11. Clever SL, Dudas RA, Solomon BS, Yeh HC, Levine D, Bertram A, et al. Medical student and faculty perceptions of volunteer outpatients versus simulated patients in communication skills training. Academic Medicine. 2011;86(11):1437-42.

12. Snow R. Real patient participation in simulations. In: Nestel D, Bearman M, editors. Simulated Patient Methodology: Theory, Evidence and Practice,. Oxford: Wiley Blackwell; 2014.

13. Weber M, Braun J, Schildmann J. Effects of a ninety-minute teaching module for fourth-year medical students on a palliative care ward with student-patient encounter. Journal of palliative medicine. 2011;14(8):940-4.

14. Jha V, Quinton ND, Bekker HL, Roberts TE. Strategies and interventions for the involvement of real patients in medical education: a systematic review. Medical Education. 2009;43(1):10-20.

15. Burford B, Greco M, Bedi A, Kergon C, Morrow G, Livingston M, et al. Does questionnaire-based patient feedback reflect the important qualities of clinical consultations? Context, benefits and risks. Patient Education and Counseling. 2011;84(2):e28-e36.

16. Greco M, Spike N, Powell R, Brownlea A. Assessing communication skills of GP registrars: a comparison of patient and GP examiner ratings. Medical Education. 2002;36(4):366-76.

17. Fields SK, Mahan P, Tillman P, Harris J, Maxwell K, Hojat M. Measuring empathy in healthcare profession students using the Jefferson Scale of Physician Empathy: health provider-student version. Journal of interprofessional care. 2011;25(4):287-93.

18. Cuddy MM, Swygert KA, Swanson DB, Jobe AC. A multilevel analysis of examinee gender, standardized patient gender, and United States medical licensing examination step 
2 clinical skills communication and interpersonal skills scores. Academic Medicine. 2011;86(10):S17-S20.

19. Wahlqvist M, Gunnarsson RK, Dahlgren G, Nordgren S. Patient-centred attitudes among medical students: gender and work experience in health care make a difference. Medical Teacher. 2010;32(4):e191-e8. 